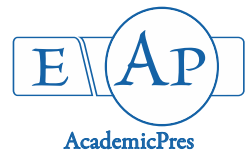

\title{
Development of Shoot Cultures from Leaf Explant of Portulaca quadrifida $\mathbf{L}$.
}

\author{
Ashutosh PATHAK, Aruna JOSHI*, Asha SHARMA \\ The Maharaja Sayajirao University of Baroda, Faculty of Science, Department of Botany, Vadodara- 390002, Gujarat, \\ India; ashutosh.pathak87@gmail.com; aruna.joshi-botany@msubaroda.ac.in(*correspondingauthor); ashaparekb1417@gmail.com
}

\begin{abstract}
Portulaca quadrifida (Portulacaceae) is an annual succulent herb having medicinal value and is consumed as a vegetable or salads in India. In the present study, leaf explants were inoculated on Murashige and Skoog's (MS) medium fortified with sucrose (3\%) and combinations of $\mathrm{N}^{6}$-benzyladenine (6-BA) and kinetin (KIN) individually and in combination with 1naphtalene acetic acid (NAA). Rapid regeneration was observed in medium fortified with combinations of $6-\mathrm{BA}(8 \mu \mathrm{M})$ and NAA $(1 \mu \mathrm{M})$ which formed $19.40 \pm 0.64$ shoots with $100 \%$ response. Variation in sucrose concentrations (4-6\%) was tried but it failed to increase the shoot number. When the optimized medium was fortified with different carbon sources viz. dextrose, glucose and maltose, they could not evoked better response and sucrose proved to be more effective for regeneration. Rooting of in vitro shoots was achieved in 1/2MS + sucrose (1\%) + indole-3-butyric acid (IBA, $2 \mu \mathrm{M})$.
\end{abstract}

Keywords: carbon source; indirect organogenesis; leaf explant; Murashige and Skoog; shoot cultures

\section{Introduction}

Portulaca quadrifida L. commonly called 'looni' which belongs to the family Portulacaceae is a small diffused, succulent, annual herb found throughout the tropical parts of India. It emits a mild pleasant smell and is used in salads or consumed as a cooked vegetable. In India, boiled leaves of the plant are mixed with sorghum or pearl millet flour in preparing a kind of bread. The plant has medicinal properties and is used to cure asthma, cough, urinary discharge, inflammation, ulcers, abdominal complaints, erysipelas and hemorrhoids (Kirthikar and Basu, 2001; Mulla and Swamy, 2010). It also has neuropharmacological effects and antifungal activities against Aspergillus fumigates and Candida albicans (Hoffman et al., 2004; Syed et al., 2010). Due to its nutritional and medicinal importance it was taken up for regeneration studies.

Leaves are commonly used explant for efficient shoot regeneration in many important medicinal plants (Joshi and Padhya, 2010; Joshi et al., 2010; Pathak and Joshi, 2017) and is also suitable for genetic transformation and protoplast fusion (Kumar et al., 2010; Xu et al., 2013). However the regeneration of plant under in vitro conditions depends on many factors, like genotype, explant, medium composition, growth regulators, gelling agent, light intensity and quality, photoperiod, temperature and vessels (Reed, 1999). The cultures developed under in vitro conditions need external carbon sources, which help in proliferation and differentiation of shoots (Kozai, 1991; Gurel and Gulsen, 1998; Nowak et al., 2004).

The aim of the present study was to optimize the medium for shoot regeneration fortified with a suitable carbon source using leaf explants of $P$. quadrifida.

\section{Materials and Methods}

\section{Plant material and surface sterilization}

Young healthy twigs of Portulaca quadrifida L. were collected from the Botanical Garden of the M.S. University of Baroda. Pieces of stem containing two to three nodes were kept in running tap water for $1 \mathrm{~h}$, and then washed with labolene (Fisher Scientific, India) for $5 \mathrm{~min}$. Surface sterilization was done with bavistin solution (0.01\%) followed by $\mathrm{HgCl}_{2}$ (Merck, India) solution (0.1\%) for $3 \mathrm{~min}$ each. Entire leaves were excised and placed abaxially on medium.

\section{Culture medium for shoot regeneration}

Murashige and Skoog (MS, 1962), medium fortified with sucrose (SRL, Mumbai, India) (3\%) served as a control for the study. This medium was supplemented with 6-BA and KIN (SRL, Mumbai, India) individually $(5$ and $10 \mu \mathrm{M})$ and in the range of $0.5-10 \mu \mathrm{M}$ with NAA $(0.5$ and $1 \mu \mathrm{M})$ (SRL, Mumbai, India). The $\mathrm{pH}$ of the medium was adjusted at 5.80 using $\mathrm{NaOH} / \mathrm{HCl}(1 \mathrm{~N})$ and agar (SRL, Mumbai, India) $(0.8 \%)$ was used as the solidifying agent. Media sterilization was done in autoclave at $121^{\circ} \mathrm{C}(15 \mathrm{psi})$ 
46

for $30 \mathrm{~min}$. All the cultures were maintained at $26 \pm 2{ }^{\circ} \mathrm{C}$ under $16 / 8 \mathrm{hr}$ (dark/light) photoperiod at $40 \mu \mathrm{mol} \mathrm{m} \mathrm{m}^{-2}$ provided by cool white fluorescent lights (Philips India Ltd., India).

\section{Effect of sucrose concentration on shoot regeneration}

Optimum shoot regeneration was achieved in MS medium supplemented with sucrose $(3 \%)$ and 6-BA $(8 \mu \mathrm{M})$ along with NAA $(0.5 \mu \mathrm{M})$. The effect of higher sucrose concentrations $(4-6 \%)$ on regeneration was also evaluated.

Effect of carbon source variation on shoot regeneration

As sucrose at 3\% concentration was considered as control, it was replaced by other carbon sources like dextose, maltose and glucose at 3\% concentration and their effect on shoot regeneration was evaluated.

\section{Rooting stage}

Eight weeks old shoots $(>3 \mathrm{~cm})$ were cultured into $1 / 2 \mathrm{MS}$ liquid medium supplemented with sucrose (1\%) and IBA $(2 \mu \mathrm{M})$. Leaves from lower nodes of the shoots were excised and they were transferred to tubes containing a filter paper bridge, with the arms of bridge dipping in liquid medium $(20 \mathrm{ml})$. Single shoot was inserted in the center of the bridge and the last 2-3 nodes were dipped in the medium. The tubes were kept in the culture room and lower portion of the tube was covered with aluminium foil till the root induction started.

\section{Statistical analysis}

All experiments were carried out in ten replicates, mean and standard error for each combination was calculated. The means were analyzed using ANOVA $(\alpha=0.05)$ and significant means were further analyzed by Dunnett's test using Graph Pad Prism 6.01.

\section{Results and Discussion}

\section{Establishment of shoot cultures from leaf explant}

Entire leaves of $P$. quadrifida when inoculated on basal MS medium as well as on medium with 6-BA and KIN individually, resulted in only swelling and failed to induce any morphogenic response. Synergistic combinations of 6$\mathrm{BA}$ and NAA when tried, the explants swelled and friable callus differentiated in all the combinations within a week. Lower concentrations of 6-BA $(0.5,1,2$ and $4 \mu \mathrm{M})$ with NAA $(0.5-1 \mu \mathrm{M})$ failed to regenerate shoots, whereas indirect organogenesis was observed in higher concentrations i.e. 8 and $10 \mu \mathrm{M}$ of $6-\mathrm{BA}$ (Table 1 ). In medium fortified with 6 -BA $(8 \mu \mathrm{M})$ and NAA $(0.5 \mu \mathrm{M})$ callus formation was observed at cut end which proliferated, turned nodular with simultaneous appearance of pink protuberances at the end of second week (Fig. 1A). They formed shoot buds by the end of fourth week (Fig. 1B) and after subculture they proliferated along with elongation into shoots during sixth week (Fig. 1C). This proliferation and elongation of shoots continued till eight week and at the end healthy shoots were observed (Fig. 1D). Optimum regeneration of $19.40 \pm 0.64$ shoots was observed in medium fortified with $6-\mathrm{BA}(8 \mu \mathrm{M})+\mathrm{NAA}(0.5 \mu \mathrm{M})$ with $100 \%$ response within eight weeks (Table 1). Further increase in 6 -BA concentration to $10 \mu \mathrm{M}$ with NAA $(0.5$ $\mu \mathrm{M})$ induced same morphogenic response, but number of shoots decreased to $16.70 \pm 0.53$. Increasing the NAA concentration to $1 \mu \mathrm{M}$ with same $6-\mathrm{BA}$ concentrations (0.5-10 $\mu \mathrm{M})$ resulted in similar response and higher concentration of 6-BA (8 and $10 \mu \mathrm{M}$ ) formed nodular callus which further differentiated $15.10 \pm 0.81$ and 13.30 \pm 0.53 shoots respectively (Table 1 ). Three week old nodular callus was fixed in FAA and the anatomy showed large number of meristemoids. These were round structures with isodimetric cells containing dense cytoplasm and prominent nucleus which were darkly stained and the differentiating shoot buds as leaf primordia (Fig. 1F). When 6-BA was replaced by KIN in combination with NAA, it induced callus which differentiated roots. This callus ceased to proliferate and even after transferring to a fresh new medium, it only increased the length and number of roots till eight week.

There are mainly two type of organogenesis i.e. direct and indirect, and the ratio of cytokinin to auxin in the medium is a key factor behind this (Skoog and Miller, 1957). In the present study, leaf explants of $P$. quadrifida differentiated callus with different morphology in presence of 6-BA and NAA. Similar results are reported for Suaeda nudiflora (Singh et al., 2004), Gomphrena globosa (Jack et al., 2005) and Hemidesmus indicus (Pathak and Joshi, 2017) where BAP and NAA influenced callus development along with variation in its morphology. In $P$. quadrifida lower concentrations of 6-BA was able to induce only callus whereas in higher concentration differentiated shoots. Similarly high cytokinin level was responsible for organogenesis from leaf explant whereas lower level formed only callus in leaf explant of Hemidesmus indicus (Pathak and Joshi, 2017). Optimum regeneration was achieved in MS medium fortified with 6-BA and NAA, and in leaf explants of Astragalus adsurgens (Luo and Jia, 1998), Beta vulgaris (Yildiz et al., 2007) and Astragalus nezaketae (Erisen et al., 2010) maximum shoots regenerated in medium having 6-BA + NAA. When KIN was supplemented in the medium, it suppressed callus formation, as well as shoots buds, and instead regenerated roots in all the combinations. Similarly in Hemidesmus indicus (Pathak and Joshi, 2017) the combination of KIN with NAA evoked less callus formation as compared to combinations of 6-BA with NAA. However contrary result was observed in leaf explants of Suaeda nudiflora (Singh et al., 2004) where medium fortified with $\mathrm{Kn}$ and NAA produced multiple shoots. Bhojwani and Razdan (1996) reported that the ratio between both the types of PGRs regulates the type of organ differentiation in vitro. In $P$. quadrifida leaf explants adopted an indirect mode of organogenesis which can become a source of somaclonal variants which enrich the genetic diversity (Patel et al., 2014). 
Table 1. Effect of BA $(0.5-10 \mu \mathrm{M})$ with NAA $(0.5-1 \mu \mathrm{M})$ on shoot regeneration from leaf explants of P. quadrifida (eight weeks)

\begin{tabular}{|c|c|c|c|c|}
\hline $\mathrm{BA}(\mu \mathrm{M})$ & NAA $(\mu \mathrm{M})$ & Callus Proliferation & No. of shoots/explant (Mean \pm S.E. $)^{a}$ & \% Response \\
\hline 0 & 0 & - & - & - \\
\hline 0.5 & 0.5 & + & - & - \\
\hline 1 & 0.5 & ++ & - & - \\
\hline 2 & 0.5 & ++ & - & - \\
\hline 4 & 0.5 & +++ & - & - \\
\hline 8 & 0.5 & ++++ & $19.40 \pm 0.64^{* * * *}$ & 100 \\
\hline 10 & 0.5 & ++++ & $16.70 \pm 0.53^{* * * *}$ & 100 \\
\hline 0.5 & 1 & + & - & - \\
\hline 1 & 1 & ++ & - & - \\
\hline 2 & 1 & ++ & - & - \\
\hline 4 & 1 & +++ & - & - \\
\hline 8 & 1 & ++++ & $15.10 \pm 0.81^{* * * *}$ & 100 \\
\hline 10 & 1 & ++++ & $13.30 \pm 0.53^{* * * *}$ & 100 \\
\hline
\end{tabular}

${ }^{a}$ Means $(\mathrm{n}=10)$ were subjected to ANOVA and significant means $\left({ }^{*}\right)$ were analyzed using Dunnett's test in comparison to control i.e. basal medium (p $\left.<0.05\right)$.

$-:$ No callus induction, + : less proliferation, ++ : medium proliferation, +++ : high proliferation, ++++ : profuse proliferation.
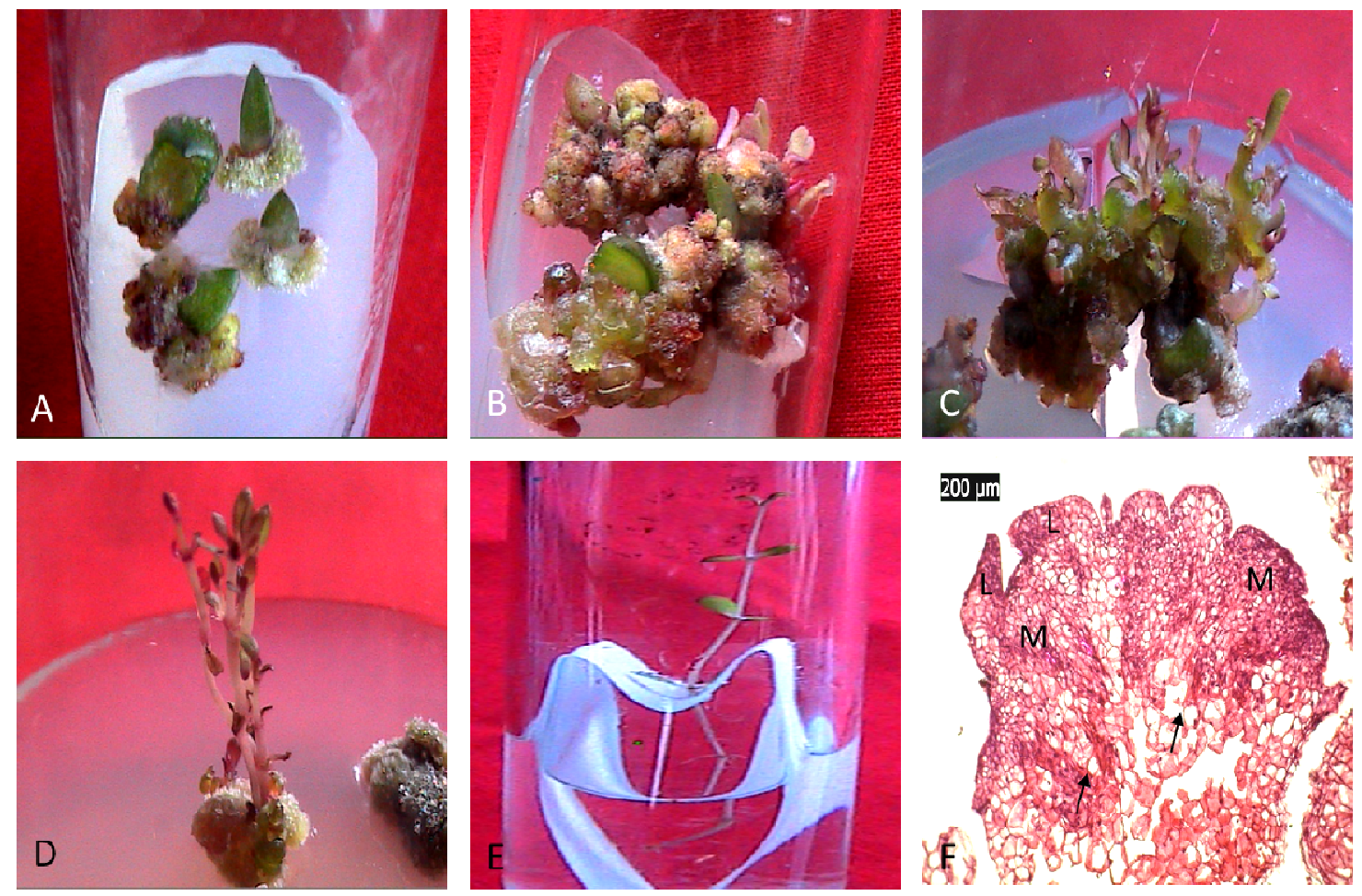

Fig. 1. Indirect organogenesis in $P$. quadrifida in MS + sucrose (3\%) + BA $(8 \mu \mathrm{M})+\mathrm{NAA}(0.5 \mu \mathrm{M})$ : (A) nodular callus with pink shoot tips after two weeks, (B) formation of shoot buds after four weeks, (C) proliferation and elongation of buds into shoots after sixth week, (D) healthy elongated shoots at the end of eight weeks, (E) rooting of shoots in $1 / 2 \mathrm{MS}+$ sucrose $(1 \%)+$ IBA $(2$ $\mu \mathrm{M})$ and (F) anatomy of nodular callus showing aadventitious shoot with leaf primordial (L), shoot meristems (M) and vascular bundles attaching to callus (arrow).

\section{Effect of sucrose concentration on shoot regeneration}

Sucrose is known to be a potent source of carbohydrate, which affects the regenerative potency of the explant. Hence optimized medium $[6-\mathrm{BA}(8 \mu \mathrm{M})$ and NAA $(0.5 \mu \mathrm{M})]$ was fortified with different concentrations of sucrose (4-6\%) and its effect on shoot regeneration was observed. Increasing the level of sucrose to $4 \%$ in medium evoked an early response and within three week callus started to differentiate shoot buds. An increase in shoot buds was observed however at the end of eight weeks $17.56 \pm 0.58$ shoots were observed in $100 \%$ cultures (Table 2). Increase in sucrose concentration to $5 \%$ and $6 \%$ induced the leaf explants to differentiate shoot buds, but number of shoots and $\%$ response was less in comparison to $3 \%$ sucrose. A total of $12.34 \pm 0.84$ number of shoots were formed in medium fortified with $5 \%$ sucrose (75\% response) and 9.12 
48

\pm 0.23 in presence of $6 \%$ sucrose $(50 \%$ response) (Table 2 ).

Generally sucrose has been used as a major carbon source which helps in maintaining the osmotic potential of culture and permits the absorption of mineral nutrients present in the medium. This is prerequisite for optimal proliferation, however it may vary from culture to culture (Nowak et al., 2004; Siwach et al., 2011). In shoot cultures of Paederia foetida (Amin et al., 2003) and Elaecarpus robustus (Rahman et al., 2004), sucrose at 3\% concentration evoked optimum growth and development of shoots. Gubiš et al. (2005) also tried different concentrations of sucrose (1-3\%) in tomato and observed that sucrose at 3\% concentration regenerated maximum shoots. Naik et al. (2010) reported that lower sucrose (2\% and 3\%) were better for shoot regeneration whereas further increase in sucrose concentration adversely affected shoot regeneration in Bacopa monnieri. This may be due to the growth suppression by osmotic stress of high concentration of sucrose, as sugars are perceived by cells as chemical signals and their high concentrations in vitro acting as stressing agents (Steinitz, 1999; da Silva, 2004). Charriere and Hahne (1998) observed the direct influence of sucrose concentration on uptake of 6-BAP into the sunflower explants, and it modified the endogenous auxins and cytokinin level which in turn triggered organogenic or embryogenic response. Nowak et al. (2004) reported that the sucrose in the medium, not only acts as a carbon source but also as an osmotic, which was also supported by findings of Karim et al. (2007) in Araria elata.

\section{Effect of carbon source variation on shoot regeneration}

Sucrose $(3 \%)$ regenerated optimum shoots and hence different carbon sources were used to evaluate their effect on shoot regeneration. When dextrose was supplemented in the medium, it evoked similar response as sucrose but resulted in inducing less number of shoots and was able to regenerate only $15.38 \pm 0.82$ shoots within eight weeks (Table 3). Presence of maltose in the medium also showed a poor response and only $11.70 \pm 0.28$ vitrified shoots were formed. Whereas the explants when inoculated on medium fortified with glucose as a carbon source it failed to induce any type of morphogenic response (Table 3 ).

Organic nutrition mostly in the form of sugars is the source of carbon and energy for growth of explants in culture media and its type as well as quantity plays a significant role in organogenesis. Earlier studies have

Table 2. Effect of sucrose variation on shoot regeneration from $P$. quadrifida leaf explant (eight weeks)

\begin{tabular}{ccc}
\hline $\begin{array}{c}\text { Sucrose } \\
\text { concentration (\%) }\end{array}$ & $\begin{array}{c}\text { No. of shoots/explant } \\
(\text { Mean } \pm \text { S.E. })^{\mathrm{a}}\end{array}$ & \% Response \\
\hline 3 & $19.40 \pm 0.64$ & 100 \\
4 & $17.60 \pm 0.65$ & 100 \\
5 & $12.90 \pm 2.07^{*}$ & 80 \\
6 & $09.20 \pm 2.44^{* * *}$ & 60 \\
\hline
\end{tabular}

${ }^{2}$ Means $(\mathrm{n}=10)$ were subjected to ANOVA and significant means $\left({ }^{*}\right)$ were sucrose concentration $(\mathrm{p}<0.05)$. reported that the sucrose is one of the important factors which controls induction and growth of shoots in vitro (Gurel and Gulsen, 1998; Gibson, 2000). Although sucrose has been the carbohydrate of choice in the majority of work on regeneration in different species, sometimes it is ineffective as the response is genotype dependent (Thompson et al., 1987; Cuenca et al., 2000). Results of variation in carbon source have depicted that sucrose is superior in comparison to other carbon sources as it differentiates healthy shoots from leaf explants. Gubis et al. (2005) used sucrose, glucose and maltose in the medium for tomato regeneration and observed that sucrose regenerated optimum shoots. The shoots regenerated in maltose supplemented medium showed vitrification and similar report by Bahmani et al. (2009) for apple in which the concentration of carbon source affected regeneration frequency and resulted in hyperhydricity of shoots in all the carbon sources. Cuenca and Vieitez (2000) reported that medium fortified with fructose showed vitrification symptoms in shoot cultures of Fagus species. Pasqualetto et al. (1988) has also reported that concentrations of carbon source and gelling agent influenced the vitrification in apple cultivars in vitro. Regeneration frequency and number of shoots varied between the carbon sources and this may be due to the complex interplay of sugar and hormone signalling in plant growth and development (Leon and Sheen, 2003).

\section{Rooting stage}

Generally in vitro rooting is affected by salts of the medium and reduced strength of MS medium (half or quarter strength) has been proved to be beneficial for rooting (Murashige, 1979; Skirvin and Chu, 1979; Garland and Stoltz, 1981; Zimmerman and Broome, 1981). In vitro shoots were excised and transferred to $1 / 2 \mathrm{MS}$ liquid medium supplemented with sucrose $(1 \%)$ and IBA $(2 \mu \mathrm{M})$. Within a week of inoculation, there was increase in shoot length. During second week, root formation was observed from the nodes and its length increased till four weeks (Fig. 1F). IBA has been used for rooting of many medicinal plants like Bacopa monnieri (Joshi et al., 2010) and Hemidesmus indicus (Pathak and Joshi, 2017). Similar reports were documented for Schinopsis balansae (Pedro et al., 2003), Bambusa balcooa (Das and Pal, 2005) and Pappea capensis (Mng'omba et al., 2007) where rooting was achieved in half strength MS medium supplemented with IBA.

Table 3. Effect of different carbon source on shoot regeneration from $P$. quadrifida leaf explant (eight weeks)

\begin{tabular}{ccc}
\hline Carbon source & $\begin{array}{c}\text { No. of shoots/explant } \\
(\text { Mean } \pm \text { S.E. })^{\mathrm{a}}\end{array}$ & \% Response \\
\hline Sucrose & $19.40 \pm 0.64$ & 100 \\
Dextrose & $15.30 \pm 0.53^{* * * *}$ & 100 \\
Maltose & $11.70 \pm 0.28^{* * * *}$ & 100 \\
Glucose & $0.00 \pm 0.00^{* * *}$ & 0 \\
\hline
\end{tabular}

${ }^{2}$ Means $(\mathrm{n}=10)$ were subjected to ANOVA and significant means $\left(^{*}\right)$ were analyzed using Dunnett's test in comparison to control i.e. medium having sucrose $(p<0.05)$. 


\section{Conclusions}

It is concluded that leaf explant of $P$. quadrifida has a high regenerative potency in medium fortified with sucrose (3\%), 6-BA $(8 \mu \mathrm{M})$ and NAA $(0.5 \mu \mathrm{M})$. The shoots regenerated through this medium will be further screened for qualitative and quantitative analysis of secondary metabolites.

\section{Acknowledgements}

This research received no specific grant from any funding agency in the public, commercial, or not-for-profit sectors. Authors are thankful to University Grants Commission (UGC), New Delhi, India for providing DRS program to the Department and Prof. Manoj Limaye, Department of Geology, Faculty of Science, The Maharaja Sayajirao University of Baroda, for clicking the photos of anatomy slide.

\section{References}

Amin MN, Rahman MM, Manik MS (2003).In vitro clonal propagation of Paederia foetida L.a medicinal plant of Bangladesh. Plant Tissue Culture 13(2):117-123.

Bahmani R, Karami O, Gholami M (2009). Influence of carbon sources and their concentrations on rooting and hyperhydricity of apple rootstock MM.106. World Applied Sciences Journal 6(11):1513-1517.

Bhojwani SS, Razdan MK (1996). Plant tissue culture: Theory and practice. Elsevier Press(Revised ed), New York, pp 483-536.

Charriere F, Hahne G (1998). Induction of embryogenesis versus caulogenesis on in vitro cultured sunflower (Helianthus annuus L.) immature zygotic embryos: role of plant growth regulators. Plant Science 137(1):63-71.

Cuenca B, Vieitez AM (2000). Influence of carbon source on shoot multiplication and adventitious bud regeneration in in vitro beech cultures. Plant Growth Regulation 1(32):1-12.

da Silva JAT (2004). The effect of carbon source on in vitro organogenesis of Chrysanthemum thin cell layers. Bragantia 63(2):165-177.

Das M, Pal A (2005). In vitro regeneration of Bambusa balcooa Roxb. factor affecting changes of morphogenetic competence in the axillary bud. Plant Cell, Tissue and Organ Culture 81(1):109-112.

Erisen S, Yorgancilar M, Atalay E, Babaoglu M, Duran A (2010). Callus induction and plant regeneration of the endemic Astragalus nezaketae in Turkey.Electronic Journal of Biotechnology 13(6):1-7.

Garland P, Stoltz LP (1981). Micropropagation of Pissardi plum. Annals of Botany 48(3):387-389.

Gibson IS (2000). Plant sugar response pathways. Part of a complex regulatory web. Plant Physiology 124(4):1532-1539.

Gubiš J, Lajchová Z, Klčová L (2005). The effect of carbon source on plant regeneration in tomato. Horticultural Science 32(1):6-8.

Gurel S, Gulsen Y (1998). The effects of different sucrose, agar and $\mathrm{pH}$ levels on in vitro shoot production of Almond (Amygdalus communis L.). Turkish Journal of Botany 22(6):363-373.
Hoffman BR, Delas A, Blanco K, Wiederhold N, Lewis RE, Williams L (2004). Screening of antibacterial and antifungal activities of ten medicinal plants from Ghana. Pharmaceutical Biology 42(1):13-17.

Jack EM, Anatasova S, Verkleij JAC (2005). Callus induction and plant regeneration in metalloohyte Silene vulgaries (Caryphyllaceae). Plant Cell, Tissue and Organ Culture 80(1):25-31.

Joshi AG, Padhya MA (2010). Shoot regeneration from leaf explants of Withaniasomnifera (L.) Dunal. Notulae Scientia Biologicae 2(1):63-65.

Joshi AG, Pathak AR, Sharma AM, Singh S (2010). High frequency of shoot regeneration on leaf explants of Bacopa monnieri. Environmental and Experimental Biology 8:81-84.

Karim MZ, Yokota S, Rahman MM, Eizawa J, Saito Y, ... Yoshizawa N (2007) Effect of the sucrose concentration and $\mathrm{pH}$ level on shoot regeneration from callus in Araria elata Seem. Asian Journal of Plant Sciences 6(4):715-717.

Kirtikar KR, Basu BD (2001). Indian medicinal plants. Dehradun, Uttaranchal, India.

Kozai T (1991). Micropropagation under photoautotrophic conditions. In: Debergh PC, Zimmerman RH (Eds). Micropropagation: Technology and application. Kluwer academic publisher, Dordrecht, Netherlands, pp 447-469.

Kumar N, Vijay Anand KG, Pamidimarri DVNS, Sarkar T, Reddy MP, ... Sopori SK (2010). Stable genetic transformation of Jatropha curcas via Agrobacterium tumefaciens mediated gene transfer using leaf explants. Industrial Crops and Products 32(1):41-47.

Leon P, Sheen J (2003). Sugar and hormone connections. Trends in Plant Science 8(3):110-116.

LuoJP, JiaJF (1998). Plant regeneration from callus protoplasts of the forage legume Astragalus adsurgens Pall. Plant Cell Reports 17(4):313-317.

Mngomba SA, Du Toit ES, Akinnifesi FK, Venter HM (2007). Repeated exposure of Jacket plum (Pappea capensis) microcutting to indole-3butyric acid (IBA) improved in vitro rooting capacity. South African Journal of Botany 73(2):230-235.

Mulla SK, Swamy P (2010). Preliminary pharmacognostical and phytochemical evaluation of Portulaca quadrifida Linn. International Journal of PharmTech Research 2(3):1699-1702.

Murashige T (1979). Principles of rapid propagation. In: Hughes KW, Hanks R, Constantin M (Eds). Propagation of higher plants through tissue culture: A bridge between research and application. Alexandria: National Tech in toServ, USDept of commerce Spring field's pp 1424.

Murashige J, Skoog F (1962). A revised medium for rapid growth and bioassay with tobacco tissue culture. Physiologia Plantarum 15(3):473-497.

Naik PM, Manohar SH, Praveen N, Murthy HN (2010). Effects of sucrose and $\mathrm{pH}$ levels on in vitro shoot regeneration from leaf explants of Bacopa monnieri and accumulation of bacoside A in regenerated shoots. Plant Cell, Tissue and Organ Culture 100(2):235-239.

Nowak BK, Miczynski K, Hudy L (2004). Sugar uptake and utilization during adventitious bud differentiation on in vitro leaf explant of 'Wegierka zwykla' plum (Prunus domestica). Plant Cell, Tissue and Organ Culture 76(3):255-260.

Pasqualetto PL, Zimmerman RH, Fordham I (1988). The influence of cation and gelling agent concentrations on vitrification of apple cultivars 
50

in vitro. Plant Cell, Tissue and Organ Culture 14(1):31-40.

Patel AK, Agarwal T, Phulwaria M, Kataria V, Shekhawat NS (2014). An efficient in vitro plant regeneration system from leaf of mature plant of Leptadenia reticulata (Jeewanti): A life giving endangered woody climber. Industrial Crops and Products 52:499-505.

Pathak A, Joshi A (2017). Indirect organogenesis from leaf explants of Hemidesmus indicus (L.) RBr.: An important medicinal plant. Plant Biosystems 151(1):1-5.

Pedro S, Hebe R, Luis M, Claudia L (2003). In vitro plantlet regeneration of Schinopsisbalansae (Anacardiaceae). Trees 17(6):542-546.

Rahman MM, Amin MN, Ahmed R (2004). In vitro rapid regeneration from cotyledon explant of native olive (Elaecaarpus robustus Roxb.). Asian Journal of Plant Sciences 3:31-35.

Reed BM (1999). Design a micropropagation system: Workshop presentation from the 1998 SIVB Congress on in vitro Biology. In Vitro Cellular and Developmental Biology-Plant 3(5):275-284.

Singh A, Cikara J, Pandya JB (2004). Plant regeneration from callus culture in Suaeda nudiflora. Indian Journal of Biotechnology 3:454456.

Siwach P, Gill AR, Kumari K (2011). Effect of season, explants, growth regulators and sugar level on induction and long term maintenance of callus cultures of Ficus religiosa L. African Journal of Biotechnology 10(24):4879-4886.

Skirvin RM, Chu MC (1979). In vitro culture of 'Forever Yours' rose. HortScience 14:608-610.

Skoog F, Miller CO (1957). Chemical regulation of growth and organ formation in plant tissues cultured in vitro. Symposia of the Society for Experimental Biology 54(11):118-130.
Steinitz B (1999). Sugar alcohols display non-osmotic roles in regulating morphogenesis and metabolism in plants that do not produce polyols as primary photosynthetic products. Journal of Plant Physiology 155(1):18.

Syed KM, Liyakha T, Ahmed MD, Paramjyothi S (2010). Neuropharmacological effects of ethanolic extract of Portulaca quadrifida Linn. in mice. International Journal of PharmTech Research 2(2):1386-1390.

Thompson MR, Thorpe TA (1987). Metabolic and non metabolic roles of carbohydrates. In: Bonga JM, Durzan DJ (Eds). Cell and tissue culture in forestry, general principles and biotechnology, Vol. 1. Springer, Netherlands pp 89-112.

Xu X, Xie G, He L, Zhang J, Xu X, ... Liu J-H (2013). Differences in oxidative stress, antioxidant systems, and microscopic analysis between regenerating callus-derived protoplasts and recalcitrant leaf mesophyllderived protoplasts of Citrus reticulata Blanco. Plant Cell, Tissue and Organ Culture 114:161-169.

Yildiz M, Önde S, Özgen M (2007). Sucrose effects on phenolic concentration and plant regeneration from sugarbeet leaf and petiole explants. Journal of Sugar Beet Research 44(1-2)1-15.

Zimmerman RH, Broome OC (1981). Phloroglucinol and in vitro rooting of apple cultivar cuttings. Journal of American Society of Horticultural Science 106:648-652. 